\title{
ALGUNAS CONSIDERACIONES CONTEXTUALES EN TORNO AL PRIMER VIAJE A JAPÓN DE JACQUES LACAN (1963) ${ }^{1}$ \\ Contextual considerations on the subject of lacan's first trip to japan (1963)
}

\section{Mercè Altimir*}

\section{Resumen}

Nuestro propósito es dar a conocer la importancia y el influjo de la cultura y el pensamiento oriental y Japón en la obra de Lacan, para cuya tarea hemos tomado el eje del viaje que realizó al archipiélago en la primavera de 1963. A partir de esta coordenada de tiempo hemos retrocedido hasta la presencia del país oriental en la obra de Sigmund Freud y hemos referido la mención del mikado y de los ainus en Tótem y tabú. En cuanto al budismo, centro del interés de Lacan en este primer viaje a las islas, Freud se mostró cauto, reticente, incluso hostil.

Lacan, en cambio, se entusiasma por oriente y se interesa por el budismo, en especial por el zen. Hemos seleccionado los comentarios que hizo a su regreso de Japón. En los mismos, el psicoanalista francés pone el dedo en la llaga y nos habla del escamoteo que sufre la sexualidad femenina en el budismo, lo que le sirve de aviso para orientar la práctica del psicoanálisis.

Palabras clave: Freud, psicoanálisis, Japón, budismo, sexualidad femenina.

Abstract

My aim in this paper is to make known the importance and influence of Eastern culture and thought and of Japan on Lacan's works. I have taken as a starting point the trip he made to this country during the spring of 1963. After this I have gone backwards to consider the presence of Japan in Sigmund Freud's works, calling attention to his mention of the Mikado and the Ainu in Totem and Taboo. Towards Buddhism, which was the focus of Lacan's interest in this first trip to the archipelago, Freud was cautious, reticent and even hostile.

Lacan, on the other hand, was enthusiastic about Orient and interested in Buddhism, especially in Zen. I have made a selection of the comments he made on his return from Japan, in which he pointed out weaknesses and commented on how feminine sexuality is eschewed in Buddhism, which he took note of in order to direct his practice in psychoanalysis accordingly.

Key words: Freud, psychoanalysis, Japan, Buddhism, feminine sexuality.

\section{EL PSICOANÁLISIS EN LOS CAMINOS DE ORIENTE}

En la época moderna el lejano Oriente ha suscitado la atención de un importante número de psicoanalistas, psiquiatras y terapeutas de orientación diversa. En nuestro caso, nos hemos propuesto el objetivo de examinar algunos de los prolegómenos, circunstancias y efectos posteriores del viaje que el psicoanalista francés Jacques Lacan (París, 19011981) realizó a Japón durante la primavera de 1963. En cierta ocasión, Freud se refirió

\footnotetext{
${ }^{1}$ Este artículo se inscribe en el Grup d’Estudi de la Traducció Catalana Contemporània (GETCC), 2009, SGR 1294, reconocido y financiado por l'Agència de Gestió i Ajuts Universitaris de la Generalitat de Catalunya, y en el proyecto “La traducción en el sistema literario catalán; exilio, género e ideología (1939-2000)”, con el número de referencia FFI2010-19851-002-01, financiada por el Ministerio de Ciencia e Innovación.
} 


\section{Mèrce Altimir}

jocosamente a la naturaleza del placer trazando una analogía del mismo con la maniobra de sacar un pie de debajo de la ropa de cama, exponerlo al frío gélido y volver a sumergirlo de nuevo en la tibieza, ligera y blanda, de las sábanas. La curva de vuelo de semejante atrevimiento es gallináceo, no cabe duda, pero útil sin duda para recordarnos que, al igual que el pícaro pie, el viajero goza ante todo, más que del viaje en sí, de la memoria del mismo. La práctica psicoanalítica pone de relieve el rodeo que realiza la pulsión en torno al hueco dejado por un objeto perdido e inalcanzable. Una parecida trayectoria de ida y vuelta, un antes y un después del viaje de 1963, es la que tratará de caligrafiar nuestra pluma en las páginas que siguen.

Jacques Lacan, el heredero fiel de Freud, según él mismo tuvo a bien reconocerse a sí mismo hasta el fin de sus días, es en la actualidad uno de los autores cuyo pensamiento ejerce una mayor influencia en las más diversas disciplinas de conocimiento: antropología, crítica literaria y cinematográfica, teoría del arte, sociología, los estudios culturales, feminismo, etc. Tampoco al pensamiento filosófico actual le resulta fácil, ni recomendable, sustraerse al influjo de quien ha sido, en numerosas ocasiones, uno de sus detractores. ${ }^{2}$ Tanto en su práctica como en su enseñanza, Lacan sostuvo una posición de salvaguarda y de voluntad de transmisión (a poder ser integral, tal como lo logra el discurso matemático) del frágil legado abierto por el descubrimiento freudiano, el cual, constantemente amenazado por las fuerzas contrarias y disolventes que suscita, corre el peligro de perderse en el olvido cuando se lo reduce a una tecnología terapéutica cualquiera. Más abajo veremos como, ya de vuelta al aula y rememorando su viaje a Japón, Lacan dirige sus dardos flamígeros contra el escamoteo de la sexualidad otra (la femenina), sea en el budismo sea en el propio psicoanálisis.

Esta posición crítica del psicoanalista francés hacia la labor clínica y teórica de otros analistas miembros de la Asociación Psicoanalítica Internacional adquirió el carácter de una batalla sin tregua, como si su persona encarnara el último baluarte que había de sostener un barco a la deriva. De la situación de deterioro de la experiencia freudiana eran responsables, a sus ojos, los sucesores oficiales del maestro de Viena, a los que tildó una y otra vez de pésimos lectores. Este sentimiento de cierre del inconsciente y de temor por la pérdida de la senda abierta por Freud no abandonaría jamás a Lacan, impulsándolo a una tarea de enseñanza ininterrumpida a la que dedicó el esfuerzo de su vida. Ello, aunque pueda ser obvio decirlo, no significa que siguiera al pie de la letra el dictado freudiano. Antes bien, no se cansó de señalar que el deber de todo analista era el de no estancarse en el saber aprendido, instándolo al esfuerzo

\footnotetext{
${ }^{2}$ Véase Cristina Marqués Rodilla en relación al pensamiento del filósofo francés Alain Badiou. Marqués Rodilla, Cristina. El acontecimiento del amor: De la insuficiencia del goce. Madrid: Biblioteca Nueva, 2006. En un paralelismo interesante, el zen constituye también un ejemplo de anti-filosofía. Según palabras de Toshihiko Izutsu: “Al zen no le gusta ser asociado con la filosofía en el sentido habitual de la palabra, pues 'filosofía' implica un pensamiento racional y discursivo y una conceptualización. En este sentido, el zen no sólo es no-filosófico sino que, más positivamente, es antifilosófico” Izutsu, Toshihiko. Hacia una filosofía del budismo zen. Madrid: Trotta, 2009:10.
} 


\section{Algunas consideraciones contextuales en torno al primer viaje a Japón}

de renovación del campo del inconsciente freudiano, cuya salud o decrepitud dependía del hecho de no perder el compás de la época.

Los conflictos de Lacan con la institución oficial fundada por Freud en 1910 no se hicieron esperar, teniendo su inicio en 1953, momento de la escisión de la Sociedad Psicoanalítica de París y de la fundación de la Sociedad Francesa de Psicoanálisis por parte de los disidentes (Lacan entre ellos). Finalmente, en 1963, y tras diez años de negociaciones, la institución internacional contestaría esta actitud de beligerancia con el veto dado a su función de didacta. En adelante ni su enseñanza ni su práctica clínica serían reconocidas como formación de analistas. Había llegado por fin el momento ansiado y temido y, al poco, la molesta Sociedad Francesa de Psicoanálisis fue disuelta y Lacan fundaba unos meses más tarde su propia escuela, la Escuela Freudiana de París, que ya no aspiraba al reconocimiento de la institución oficial internacional. Precisamente en las vísperas del viaje a Japón, la tensión entre la filial pretendiente y la asociación internacional había llegado a su punto álgido anunciando el irreversible desenlace que llevó a la ruptura. Teniendo en cuenta que Lacan iba a abordar en el curso siguiente un seminario que tituló "Los nombres del padre" y en el que se proponía hablar del monoteísmo y de la religión judía - temática que aludía al peligro de transformación de la comunidad analítica en una institución similar a la de la Iglesiaeste paseo por el archipiélago oriental y la cultura budista debió de significar un contrapunto oxigenante, permitiéndole un cierto respiro y un distanciamiento necesario de los graves sucesos en los que se hallaba envuelto. Frédéric Lenoir, en El budismo en Occidente (2000), señala la brecha epistemológica que existe entre el budismo, edificado sobre la experiencia personal de un fundador, y las religiones reveladas, las cuales, además, cuentan con una institución centralizada que tiene a su cargo velar por la ortodoxia del dogma intemporal. En el caso del budismo, por el contrario, "el mensaje de Buda formula, por supuesto, algunas verdades fundamentales, pero apela a la experiencia y a la razón individuales para validar la creencia”. ${ }^{3}$

Lo mismo que su antecesor vienés, Lacan sobresale por su volumétrica erudición, su resuelta ambición y por una curiosidad infatigable. En otros aspectos, en cambio, como es el caso que intentamos analizar en estas páginas, la actitud de uno y otro faro del pensamiento del siglo XX mantenían pareceres y gustos claramente desemejantes.

Como se sabe, la mayor parte de la enseñanza de Lacan —nos referimos a los seminarios de enseñanza - fue exclusivamente oral. Sólo con posterioridad, aunque esta tarea nunca fue llevada a cabo por la mano de quien dictó la enseñanza, las grabaciones y los registros estenográficos de las sesiones han sido puestos por escrito. La publicación oficial de los seminarios — todavía incompleta—, y de otros textos del psicoanalista francés, la dirige desde el inicio Jacques-Alain Miller en la editorial Seuil francesa. La editorial Paidós se encarga regularmente de su traducción al castellano.

Durante el transcurso de la sesión correspondiente al 20 de marzo de 1963, justo antes de su partida de viaje con destino a Japón, Lacan evoca una vez más — no sería ni

\footnotetext{
${ }^{3}$ Lenoir, Frédéric. El budismo en Occidente. Barcelona: Seix Barral, 2000:18.
} 


\section{Mèrce Altimir}

la primera ni la última vez que esto tendría lugar a lo largo de los 30 años en que ocupó la tarima — La tierra baldía, el largo poema de T.S. Eliot publicado en 1922 (el mismo año en que se publicó el Ulises de Joyce y dos de las novelas que integran À la recherche du temps perdu de Proust, hitos de la literatura del siglo XX). Este poema, a tenor de las significativas marcas que dejó en su obra, debió de ser leído con fruición por parte de de Lacan. En la ocasión referida, el psicoanalista evoca el pasaje de Tiresias, "old man with wrinkled female breasts”, el vidente ciego que, excepción entre las excepciones, y tal como lo plasmó Ovidio en Las metamorfosis, contaba con la experiencia del goce del hombre y de la mujer. Las notas que incluyó Eliot en el poema nos recuerdan el interés antropológico del ilustre ciego, que en La tierra baldía aparece ya anciano y con tetas, un recuerdo quizás de su paso por la feminidad. La ficción de Tiresias nos propone el interesante interrogante de si al ser humano le resulta posible esta transformación en uno u otro sexo. En tanto psicoanalistas, sabemos que la carne (el organismo animal sexuado en macho y hembra) no es el cuerpo, y que no hay significante en el inconsciente que nos defina como tales. El sujeto, por consiguiente, tratará de interrogar su identidad sexuada en el Otro del lenguaje, mas, al no obtener respuesta a su pregunta, se deberá conformar con el remedio de hacer de hombre o hacer de mujer al modo de los mandatos siempre circunstanciales y variables de su cultura y del momento histórico en que le ha correspondido vivir. Tal como se explicará más adelante, Lacan está en estos momentos de su enseñanza envuelto en un proceso de revalorización de la subjetividad femenina y señalando la mayor libertad de las analistas mujeres en la situación transferencial de la cura. Por este motivo, la referencia a las tetas del visionario, aquél que es capaz de ver más allá de los objetos del mundo ordinario, resulta elocuente. Con estas palabras, Lacan dirige una advertencia a sus alumnos practicantes y un elogio a las colegas femeninas. Paso a paso, tratará de definir lo que dará en llamar una "verdadera" mujer (difícil cuestión que le servirá al menos para desenmascarar lo que la mujer, aun pareciéndolo, no es). Era ésta, precisamente, una de las preguntas que Freud había dejado pendientes, de modo que tratando de responderla Lacan seguía, como en otros casos, la senda de su maestro al mismo tiempo que la enriquecía.

Volviendo al poema y al adivino, el anciano visionario contempla la escena del mundo con ánimo triste. Todo es mediocridad y falta de coraje en esta tierra árida sin lluvia ni torrentes. Sabe demasiado bien que el galán chupatintas no logrará ni tan siquiera pulsar una pequeñísima arteria del corazón femenino. En cuanto a ella, cuando concluya el affaire y su pareja por fin se evapore, ni una pizca de añoranza guardará su recuerdo. La satisfacción de una apetencia hueca, pobre y resabida, sin misterio, la deja, cómo no, virgen de corazón

Ella se vuelve y se mira un instante en el espejo sin apenas advertir que su amante se ha marchado; a su mente acude incompleto un pensamiento: "Bien, asunto concluido; menos mal que ya ha pasado". 


\section{Algunas consideraciones contextuales en torno al primer viaje a Japón}

Cuando una mujer hermosa cae en la insensatez

y otra vez, a solas, se pasea por el cuarto,

alisa su peinado con mano automática

y pone un disco en el gramófono ${ }^{4}$

El largo poema de Eliot había sido una referencia de Lacan desde el inicio de su enseñanza. Aparece ya en el llamado primer discurso de Roma, la conferencia inaugural de 1953 que se publicaría en el volumen de los Écrits en 1966 bajo el título de "Función y campo de la palabra y del lenguaje en el psicoanálisis". ${ }^{5} \mathrm{Al}$ igual que el poeta, Lacan se interrogaba por ese entonces acerca de un acto capaz de devolver la vida a la empobrecida existencia del sujeto moderno. Si hemos insistido en esta referencia es porque Eliot no era para nada un lego en relación al pensamiento oriental y, según parece, precisamente en la época en que componía La tierra baldía habría confesado a Gabriela Mistral que estuvo a punto de convertirse al budismo, descartando finalmente la idea. ${ }^{6}$ El poema, que tanto entusiasmó a Lacan, traspira profusamente ese amor por el oriente asiático de su autor.

Las referencias al budismo, y más en concreto, al budismo zen, son también una reiterada presencia en la serie de artículos y seminarios que arrancan de 1953 y terminan con la muerte de Lacan, acontecida en 1981. No era el psicoanalista francés el primero de su disciplina en interesarse en oriente ni en el zen. Uno de sus ilustres contemporáneos en esta senda fue Erich Fromm, del que muchos recordamos el libro que escribió conjuntamente con el difusor más importante de la escuela de la iluminación súbita en occidente entre los años treinta y sesenta, el japonés D. T. Suzuki, Zen Buddhism \& Psychoanalysis, libro publicado en Nueva York en 1960. La obra era fruto de un seminario impartido en el Departamento de Psicoanálisis de la Escuela de Medicina de la Universidad Autónoma de México en Cuernavaca en el año 1957 y que fue traducida al castellano en 1964 bajo el título Budismo zen y psicoanálisis. ${ }^{7}$ Veremos más abajo que el interés de Lacan por oriente, lejos de ser un flirt pasajero fue un amor de por vida.

Especialista en el Corán, el sufismo y otras vías de pensamiento orientales como el taoísmo y el zen, el japonés Toshihiko Izutsu, en Hacia una filosofía del budismo zen (2009), plantea la cuestión central de esta escuela, surgida de la confluencia del budismo de origen indio con el pensamiento chino, del modo siguiente:

En vez de formular su interrogación acerca del hombre de la forma aristotélica: “¿Qué es el hombre?”, el budismo zen empieza preguntando directamente: “¿Quién soy yo?”. El asunto en cuestión no es el problema clásico de la

\footnotetext{
${ }^{4}$ La traducción es de José Luís Palomares. Eliot, Thomas Stearns. La tierra baldía. Madrid: Cátedra. 2005:245.

${ }^{5}$ Lacan, Jacques. Escritos. Madrid: Siglo XXI, 1995:vol. I, 227-310.

${ }^{6}$ Según detalla Viorica Patea en la introducción de la edición de Cátedra. Eliot, Thomas Stearn. Op. cit., 34.

${ }^{7}$ Traducido por Julieta Campos al Castellano en 1964. Fromm, Erich; Suzuki, Daisetsu Teitarô. Budismo zen y psicoanálisis. México: F. C. E., 1964.
} 
naturaleza del hombre en general, sino el problema infinitamente más personal e íntimo de quién es este sujeto humano que, existiendo en este modo aquí y ahora en un sistema espacio-temporal, plantea la pregunta acerca de sí mismo”8

Nos ha interesado incluir este pasaje porque, al destacar, como hace su autor, la importancia del caso particular, tan a menudo oscurecido por la interrogación filosófica, consigue poner de manifiesto una confluencia entre el practicante del psicoanálisis y el del zen. En uno y otro caso la tarea práctica persigue la producción de la sorpresa, la construcción de un lugar capaz de dar cobijo al acontecimiento inesperado. En otras palabras, tratan de contrarrestar la existencia rutinaria mediante la contingencia creativa, y lograrlo además en la vida ordinaria de cada día.

Izutsu plantea que este tipo de búsqueda del silencio, de una realidad situada más allá del conocimiento, no sólo no es exclusiva del zen, sino que se da en muchas culturas. ${ }^{9}$ Las líneas que siguen tratan de dar a conocer un momento concreto de un itinerario mucho más largo por cuyo sendero Lacan trató de ubicar esa experiencia que llamará de lo real en la cura psicoanalítica. Al no ser un concepto, esta dimensión rehúye toda definición posible, lo cual no nos impide que podamos hablar de ella. Lo real, entonces, es lo que no puede decirse, lo imposible o, también, el acontecimiento no previsible. Lo real es un afecto en el cuerpo vivo que escapa, verdadero burlón, a su puesta en palabras.

Pero antes de pasar a Lacan nos gustaría indagar qué representó Japón y el budismo para su antecesor vienés. Sabemos que el lejano oriente asiático, con su fardo de modas orientalistas y su llamado al conocimiento erudito, aterrizó en Europa en distintas oleadas. Ya cercanos al momento histórico de Freud, filósofos como Schopenhauer y Nietzsche mostraron un ardiente interés por la religión del despierto, aunque más adelante el segundo, en parte por haberla asimilado el pensamiento pesimista de El mundo como voluntad y como representación (1818), acabó atacándola. Esta interpretación desencantada del budismo frente a la vida debió de influir negativamente en el ánimo de Freud, lector de Schopenhauer. El austríaco tenía la firme voluntad de inscribir el psicoanálisis en la ciencia y la razón, y de plantar batalla en la defensa de una existencia más gozosa y audaz, lo cual suponía el trabajo de averiguar quién se beneficiaba de los sacrificios que la cultura demanda al sujeto. El término de principio de nirvana con que bautizó la tendencia de la pulsión al equilibrio y la ausencia de tensión (la pulsión de muerte), es sin duda una marca notoria de la introducción y difusión del conocimiento del budismo en occidente durante el XIX y la primera mitad del XX. Es importante señalar, finalmente, el hecho de que, contradiciendo la corriente general de declive de la curiosidad de los filósofos occidentales por esta corriente de pensamiento asiática ocurrida en la segunda mitad

\footnotetext{
${ }^{8}$ Izutsu, Toshihiko. Hacia una filosofía del budismo zen. Madrid: Trotta. Pliegos de Oriente, 2009:13-14.

${ }^{9}$ Al respecto, señala: "Estos y otros casos similares de actividad 'creativa', conocidos no sólo en el Extremo Oriente sino en casi todas las culturas del mundo, constituyen ejemplos de la realización de la 'no-mente' en el nivel de la vida cotidiana. Pero en este nivel, la realización de la 'no-mente' no es sino un fenómeno esporádico y más bien excepcional”. Izutsu, Toshihiko. Op. cit., 25.
} 


\section{Algunas consideraciones contextuales en torno al primer viaje a Japón}

del siglo XIX, restarían sin embargo algunos casos, como el de Martin Heidegger, que conservarían vivo el interés. Precisamente el filósofo de la Selva Negra dejó un influjo notorio en el pensamiento lacaniano.

Por otra parte, merece la pena recordar la estrecha amistad que unió a Freud con el escritor Romain Rollaind, premio Nobel de literatura de 1915 y autor de diversos relatos influidos por el hinduismo. A continuación examinaremos con mayor detenimiento la presencia concreta de Japón y del budismo en la obra freudiana.

\section{JAPÓN, UN DETALLE EN EL OCÉANO DE REFERENCIAS DE FREUD}

Como sabrá todo aquél que conozca la obra freudiana, las menciones al lejano oriente son prácticamente inexistentes. Japón y su cultura, en concreto, reciben en tan solo un par de ocasiones la atención de su pluma. Con Lacan, en cambio, la manifestación del influjo oriental dará, como veremos, un salto cualitativo.

Existen razones históricas evidentes que explican unas actitudes tan opuestas, así como la reticencia y general desconocimiento mostrados en relación al mundo oriental por parte del fundador. El país del sol naciente estuvo, desde 1603, cerrado casi herméticamente al mundo exterior durante más de dos siglos y medio, abriendo sus fronteras finalmente de nuevo hacia 1865, momento en que el nuevo gobierno Meiji se hizo con el poder y abolió el shogunato Tokugawa, responsable de la política de cierre del país. Cuando uno cae en la cuenta de que Freud nació en 1856, comprende fácilmente que, para el vienés, las noticias sobre el país oriental tuvieron que ser pobres y parcas durante su juventud. Japón fue una nación remota, aislada y llena de misterios para los europeos nacidos a mediados del siglo XIX. A tocar de su término y en las primeras décadas del pasado siglo los renovados contactos con la cultura del archipiélago provocarían la oleada de japonismo que recorrería Europa y que tendría una influencia artística fundamental en la pintura y las bellas artes. Queda justificado, pues, el pequeño lugar que Japón ocupa tanto en el pensamiento como en las inclinaciones del fundador.

Sin embargo no podemos limitar las razones de su distanciamiento a la esfera del contexto histórico supraindividual. Existen además otros poderosos motivos personales en Freud que lo hacían reticente al budismo y al pensamiento chino o indio, cuyo conocimiento ya había sido introducido en Europa desde el siglo XVIII y había ocupado la mente de los filósofos (Hegel, Schopenhauer y Nietzsche). Estos apuntan al lugar preeminente que ocupaba en el corazón de Freud la religión de Abraham y de Moisés. En este sentido, concedió un lugar de superioridad, en cuanto a resorte de la sublimación, a las religiones monoteístas. Veremos que en el caso de Lacan, por el contrario, hay una puesta en duda de las virtudes de esta exigencia extrema y una búsqueda concomitante de un goce suplementario, femenino, que enlaza con su interés por el budismo y el pensamiento oriental en general. Lacan dará cabida, en el pensamiento, a la lógica diferente, no dualista, de algunas otras grandes corrientes religiosas ajenas al monoteísmo.

La psicoanalista Colette Soler constata en las páginas de su libro Lo que dijo Lacan sobre las mujeres (2006) que la lista de manifestaciones de la experiencia de un goce femenino, un goce real que escapa al concepto y a la razón, se detuvo en las pocas 


\section{Mèrce Altimir}

menciones ofrecidas por Lacan, entre las que se cuentan algunas experiencias místicas o el acceso a la existencia formulado por Kierkegaard. La autora lamenta el hecho de que, después de Lacan, apenas hemos enriquecido la serie. ${ }^{10}$ Ella añade a la lista la mujer pobre (impelida a hacer resaltar el goce de no tener) y la mujer abstinente.

Oriente nos habla de una experiencia de comunicación que contrasta con la propiamente occidental, usualmente fragmentada entre un sujeto-espectador y un objeto-espectáculo de representación

Este aspecto positivo de la disciplina zen es conocido en la terminología tradicional de la espiritualidad asiática como el "llegar a ser la cosa”. La idea de que el hombre llega a ser la cosa ha desempeñado un papel sumamente importante en el Lejano Oriente en varios campos de la cultura como la religión, la filosofía y las bellas artes. En efecto, no es exagerado decir que no se logrará comprender el espíritu de dicha cultura sin una plena comprensión de este principio. ${ }^{11}$

Por todo lo que hemos dicho hasta ahora, no tiene nada de extraño que las menciones a Japón en la obra del fundador de la disciplina del inconsciente sean casi nulas. Veremos que se limitan, tal como ya hemos señalado más arriba, a dos, la institución del mikado y el oprimido pueblo ainu, ambas tomadas de La rama dorada de James George Frazer, la exitosa obra de antropología publicada por primera vez en 1890 y de la que Freud, como tantos otros europeos, fue un lector entusiasta.

\section{PRESENCIAS}

Estas menciones aparecen en Tótem y tabú (1913), una sus obras más controvertidas desde el punto de vista de la antropología y de las ciencias sociales, pero una de las más queridas por Freud. "No escribí nada con más convicción, salvo la interpretación de los sueños”, declara a su amigo y discípulo Ferenczi. ${ }^{12}$

La rama dorada, fuente de Freud para sus referencias japonesas, comenta la figura del mikado y su aurea de misterio. Al parecer, el emperador japonés no sólo era para su pueblo una fantasmagoría apenas existente — como la de las monjas de clausura de nuestra tradición-, sino que además se le obligaba a adoptar la consistencia pétrea de la estatua. Veamos unos fragmentos de la descripción de Frazer

Se considera su persona, si se nos permite expresarlo así, a modo de centro dinámico del universo, del que irradian las líneas de fuerza en todas direcciones del cielo, de tal modo que un movimiento de su cabeza o el solivio de su mano afectan al instante y puede alterar seriamente alguna parte de la naturaleza. Él es el punto de apoyo del cual depende el equilibrio mundial, y la menor irregularidad por su parte puede deshacer dicho equilibrio. [...]

En tiempos antiguos estaba obligado a sentarse en el trono durante varias horas todas las mañanas, con la corona imperial puesta sobre la cabeza y a quedar inmóvil, semejante a una estatua, sin mover mano ni pie, ni la cabeza, ni los

\footnotetext{
${ }^{10}$ Soler, Colette. Lo que Lacan dijo de las mujeres. Buenos Aires: Paidós, 2006:27.

${ }^{11}$ Isutzu, Toshihiko. Op. cit., 77.

${ }^{12}$ Zafiropoulos, Markos. La declinación del padre (1938-1953). Buenos Aires: Nueva Visión, 2002:90.
} 


\section{Algunas consideraciones contextuales en torno al primer viaje a Japón}

ojos, ni en absoluto parte alguna de su cuerpo, pues mediante esto se pensaba que podría conservar la paz y la tranquilidad en su imperio; si desgraciadamente se movía o tendía una mirada en cualquier dirección de sus dominios, estallaría la guerra, el hambre, los incendios o alguna catástrofe pronta a desolar el país. ${ }^{13}$

Tal como se puede apreciar, la estrategia política consiste en inventar una figura imposible que no estaría atravesada por la falta. Aquello que vendría precisamente a perturbar el orden y la paz sería que el mikado deseara algo, por ejemplo, que detuviera su mirada en un lugar más que en otro, que hiciera una elección. Al mismo tiempo, se borra de su persona todo rasgo de impureza. Se le asea de noche mientras duerme, una táctica de negación de su realidad de ser vivo y, como tal, productor de excrecencias inútiles. Una epistemología que se asemejara a esta política exigiría el saber absoluto, sin resto. Tal como señala Frazer, y repite Freud, el mikado no es un déspota que gobierna sobre unos súbditos esclavizados. Más certeramente es un pelele creado por sus fieles servidores, que igual que disecan a un lepidóptero no dudan en momificar a su supuesto soberano. Es por esta razón, como nos señala el psicoanalista japonés Shingu Kazushige, que esta maniobra no hay que leerla únicamente desde la antropología sino principalmente con clave política. Responde a la voluntad cómplice de una minoría que detenta el poder real y de una masa anónima que la obedece.

La contrapartida de la referencia al mikado y a su inmovilidad de ser sin falta ni deseo la constituye la mención de los ainus, los primitivos pobladores del archipiélago que fueron paulatinamente desplazados hasta terminar confinados en la isla nórdica de Hokkaidô, lugar donde, en la actualidad, todavía sobreviven del modo más precario. Los ainus, según Shingu, han conservado el animismo primitivo ahogado por la operación de transformación política que se instaura con el mikado. Continuando con el pensamiento del psicoanalista japonés, un sector del posterior budismo, llegado a las islas alrededor del siglo VI, actuará de recipiente de esta corriente residual. Freud se refiere en Tótem y tabú a la costumbre ainu de matar ritualmente a un oso, representante de un mensajero divino, y comérselo a modo de banquete totémico.

En cuanto al budismo, su historia en las islas es demasiado compleja como para liquidarla de forma simple. Tal como ocurre en circunstancias parecidas de discordancia entre corrientes religiosas y devocionales, y entre estamentos y roles sociales, habrá también en las islas una religión oficial y otras de populares, sean sintoístas o budistas, o una mezcla, como fue tan frecuente, de ellas. Es bueno recordar esta distinción entre religión oficial y versiones populares porque de nuevo es en la religión todavía no institucionalizada del budismo, en los movimientos iconoclastas del zen, donde Lacan tratará de hallar resonancias a su búsqueda de una técnica de la palabra que toque algo de lo real del sujeto. En este sentido, la exagerada fantasmagoría del mikado, su institución, y su presentación en el imaginario se vuelve un motivo fácil de parodia. La seca ley de la objetividad y la igualdad queda retratada

\footnotetext{
${ }^{13}$ Frazer, James George. La rama dorada. México: F.C.E., 1944:207-208.
} 


\section{Mèrce Altimir}

de la manera más irrisoria, no pudiendo silenciar el horror de la amenaza totalitaria. El detalle del residuo, por contraste, aquello que la estatua trata de borrar, cobra un valor insospechado. Hacía él apuntará tanto el zen como la lógica del no-todo de la feminidad (uno de los nombres de lo real) en el psicoanálisis de orientación lacaniana.

Las referencias de Frazer proceden del libro de Engelbert Kaempfer (16511716), The History of Japan, publicado en Londres en 1727. El explorador germano habría sido uno de los escasos extranjeros que obtuvieron el permiso para residir en Japón durante el cierre Tokugawa. Fueron en total dos años, de 1690 a 1692, pasados en un lugar circunscrito y vigilado de la ciudad de Nagasaki y con posibilidades de movilidad muy limitada. Es de suponer, por consiguiente, que las noticias que da este autor sobre la figura del mikado proceden, tal como bien señala Shingu, de documentos escritos y en ningún caso del conocimiento directo, circunstancias que deben tenerse en cuenta a la hora de valorar sus aportaciones, pues las descripciones que ofrece no pueden ser del todo fidedignas. ${ }^{14}$ Por fuerza han de de estar teñidas del muro ideológico y político que construyó el shogunato en torno al emperador.

En cuanto a las fuentes de Frazer acerca de los ainus, proceden de las numerosas publicaciones del reverendo inglés John Batchelor (1854-1944), que convivió largo tiempo con ellos, aprendió su lengua con fines de apostolado y difundió su cultura en el ámbito anglosajón.

\section{AUSENCIAS}

Hasta aquí las menciones. Al ser las ausencias tanto o más elocuentes que las mismas presencias, no resistiremos la tentación de señalar las que hasta el momento presente nos han parecido más significativas. Nos resulta sorprendente que existiendo las escrituras china y chino-japonesa como instrumentos vivos (a las que cabe añadir, el precioso ejemplo del histórico manyogana), ${ }^{15}$ Freud haya aprendido del egiptólogo Jean-François Champollion —el descubridor de la clave que descifró la escritura de la lengua muerta de los egipcios - el mecanismo del rebus, gracias al cual unas pocas letras-imágenes son usadas para la representación de las cadenas sonoras del lenguaje articulado. Este funcionamiento, al posibilitar el paso del pictograma al fonograma, constituye la base del modo operativo de cualquier sistema de escritura inventada por el hombre. La explicación que se nos ocurre en relación a este anacronismo es el peso tan grande que conservaba todavía en la época de la escritura de La interpretación de los sueños (1899) el mito del Egipto antiguo y su tierra de maravillas. Tanta era la fascinación ejercida por la tierra del Nilo sobre muchos de los coetáneos de Freud que toda otra escritura que se pareciese quedaba eclipsada tras su nube dorada. Pero como

14 Shingu, Kazushige. "Freud, Lacan and Japan". The Letter: Lacanian Perspectives on Psychanalysis, 34, 2005. Kaempfer viajó en dos ocasiones a Edo y se entrevistó con el shogun Tokugawa Tsuneyoshi, pero el emperador residía en la corte de Kioto.

${ }^{15}$ Uso fonemático de los caracteres chinos utilizado, entre otros recursos, por los japoneses en el momento de la introducción de la escritura china en Japón alrededor del siglo VI. 


\section{Algunas consideraciones contextuales en torno al primer viaje a Japón}

esta cuestión nos llevaría lejos, el lector nos permitirá que nos alejemos de ella y pasemos a otra ausencia significativa. Nos referimos a la influencia del sustrato religioso. Se han escrito numerosos trabajos acerca del influjo de la religión judía en las concepciones teóricas de Freud. Lacan, particularmente, le achaca que, a pesar de su posición crítica con las creencias, no superara la glorificación del padre. Nos conviene recordar aquí tanto las críticas feministas a la perspectiva freudiana sobre la mujer como el lugar marginal que ocupan las mujeres en las instituciones sociales, también en el budismo. Hablaremos de ello cuando comentemos un pasaje del sutra del loto.

El vienés sentía una gran admiración por Romain Rolland — seguramente uno de los interlocutores a los que estaba más dispuesto a escuchar en relación al tema de oriente - tanto por el hombre y su combate pacifista como por el escritor. Sin embargo, está claro, y así lo dejaría escrito, que no compartía sus puntos de vista ni sus pasiones. La claridad conceptual expresada en palabras era la meta de Freud y, por consiguiente, "el ombligo del sueño", expresión con la que bautizó el residuo no interpretable, quedaba fuera de su esfera de su tarea, no llegando a determinar su función en la clínica. Su actitud frente a lo inarticulado era más bien de defensa. Escribirá en El malestar de la cultura (1930):

¿Qué título tiene este sentimiento [el sentimiento oceánico defendido por Romain Rolland como fundamento del origen de la religión] para ser considerado como la fuente de las necesidades religiosas?

[...] No se podría indicar en la infancia una necesidad de fuerza equivalente a la de recibir la protección del padre. De este modo, el papel del sentimiento oceánico, que —cabe conjeturar— aspiraría a restablecer el narcisismo irrestricto, es esforzado a salir del primer plano. Con claros perfiles, sólo hasta el sentimiento del desvalimiento infantil uno puede rastrear el origen de la actitud religiosa. Acaso atrás se esconda todavía algo, más por ahora lo envuelve la niebla. ${ }^{16}$

Este "acaso" de la última frase cierra tanto como suscita nuevas investigaciones. Destacaremos finalmente otra cita en la que Freud expone por qué considera que la religión judaica ocupa un lugar de privilegio en tanto resorte del proceso de civilización:

De sus limitadas noticias quizá pueda agregar, todavía, que el caso de la fundación religiosa mahometana le parece una repetición abreviada de la judía, como cuya imitación entró en escena. Parece, en efecto, que el profeta tuvo originariamente el propósito de adoptar de manera plena el judaísmo para sí y para su pueblo. La reconquista del grande y único padre primordial produjo entre los árabes una elevación extraordinaria de la conciencia de sí, la cual condujo a grandes éxitos universales, mas, también, se agotó en estos. Alá se mostró mucho más agradecido hacia su pueblo elegido que, en su tiempo, Yahvé hacia el suyo. Pero el desarrollo interior de la religión nunca se detuvo pronto, acaso porque le faltó el ahondamiento causado, entre los judíos, por el asesinato del fundador de la religión. Las religiones

\footnotetext{
${ }^{16}$ Freud, Sigmund. El malestar en la cultura. Obras completas, vol. XXI, 73. Buenos Aires: Amorrortu, 1985.
} 
orientales, en apariencia racionalistas, son por su núcleo un culto de los antepasados y, por tanto, se detienen en un estadio anterior a la reconstrucción del pasado. ${ }^{17}$

Lacan divergirá de su maestro. Aunque ambos pensadores se interesaron por la religión comparada, de la que uno y otro se esforzaron en extraer un saber, su visión, sin embargo, no fue la misma. El francés supo leer algo que a Freud le pasó desapercibida: el valor de una dimensión que escapa a la palabra y que es cercana al silencio. Por otro lado, queremos subrayar que el dicho freudiano en relación a las religiones orientales en tanto aparentemente racionalistas se fundamentaba en la defensa que hicieron de ellas los responsables del movimiento ilustrado y laico como Voltaire y sus continuadores decimonónicos, los cuales instrumentalizaron la religión asiática con el objetivo de atacar al cristianismo. Esa fue, por ejemplo, una de las posturas adoptadas por Nietzsche. ${ }^{18}$

Freud, en El malestar de la cultura, plantea el difícil callejón sin salida a que conduce la sublimación civilizadora ¿Cómo entender que podría tener el fin paradójico de acabar con la vida cuando, en su propósito inicial, está destinada a conservarla? En contraste con ello, tenemos al monje zen, que halla la felicidad en lo ordinario de la vida cotidiana. Este problema de la civilización y este ejemplo de culta simplicidad explican en buena parte el interés de Lacan por el pensamiento oriental, y en concreto, por lo que ahora nos ocupa, el budismo.

\section{LACAN: OTRA MIRADA Y OTRO ENTUSIASMO EN RELACIÓN A ORIENTE}

Una vez examinado el legado de Freud, damos paso a Lacan. El analista francés estudió lengua china en la Escuela de Lenguas Orientales de París durante el tiempo de la ocupación alemana. Ya ello supone un salto respecto a su antecesor, pues, tal como ya hemos señalado, representa desplazarse del mito del Egipto resucitado a la curiosidad que despierta una escritura viva. Su profesor fue Paul Demiéville (Lausanne, 1891; París, 1979), un renombrado especialista en nada menos que budismo zen. Además del chino, este estudioso conocía el sánscrito y el japonés. Entre 1926 y 1930 residió en la Maison Franco-Japonaise de Tokio y participó en calidad de redactor jefe junto a los prestigiosos sinólogos Sylvain Lévi y Takakusu Junjirô en el Hôbôgirin, dictionnaire encyclopédique du bouddhisme d'après les sources chinoises et japonaises (aparecido en fascículos en 1929, 1930 y 1937). En 1931, de vuelta a París, y hasta 1945, imparte clases de lengua china en la École des Langues Orientales, lugar donde lo conoce Lacan. A continuación, transcribimos la evocación que el psicoanalista realiza de su maestro en 1963

\footnotetext{
${ }^{17}$ Freud, Sigmund. Moises y la religión monoteísta. Op. cit., vol. XXIII, 89.

${ }^{18}$ Frederich Nietzsche escribe ya en El anticristo (1888): El budismo es cien veces más realista que el cristianismo, lleva en su cuerpo la herencia de un planteamiento objetivo y frío de los problemas, viene después de un movimiento filosófico que había durado unos cientos de años, cuando él llega el concepto de "Dios" está ya eliminado. El budismo es la única religión auténticamente positivista que la historia nos muestra, también incluso en su teoría del conocimiento (un fenomenalismo riguroso), él no nos dice ya "lucha contra el pecado", sino, dando totalmente la razón a la realidad, "lucha contra el sufrimiento”. Lenoir, Fréderic. Op. cit., 121-122.
} 


\section{Algunas consideraciones contextuales en torno al primer viaje a Japón}

Antes de que me interesara en el japonés, la suerte hizo que tomara los caminos adecuados y que explicara, con mi buen maestro Demiéville, en los años en que el psicoanálisis me dejaba más tiempo libre, aquel libro llamado El loto de la verdadera ley, que fue escrito en chino por Kumarâjiva para traducir un texto sánscrito. ${ }^{19}$

Encontramos en estas líneas una referencia al sutra del loto, una de las escrituras más importantes de la tradición mahayana. Conviene también que recordemos la tradición zen y su rechazo al saber libresco. Habitado por un sentimiento similar, en el momento de emprender el viaje a Japón, Lacan expresa el deseo de reencontrar una viveza de la experiencia que ningún libro podrá substituir

Como algunos saben, vuelvo de un viaje que me ha aportado algunas experiencias, y también lo esencial, en todo caso la proximidad, la visión, el encuentro con algunas de esas obras sin las cuales el estudio más atento de los textos, de la letra, de la doctrina, en particular en este caso la del budismo, no puede sino permanecer como algo seco, incompleto, sin vida (Lacan, 2006:232).

Resulta significativa esa necesidad expresada por Lacan de ir más allá de los polvorientos libros del pasado para vivir la actualidad presente de un pensamiento, de buscar un contacto que supere la distante lejanía propia del lector. Su actitud nos hace venir a la memoria el rechazo tan marcado hacia lo libresco expresada por algunos pensadores taoístas. Compárese, por ejemplo, con este pasaje del carretero Piang de Zhuangzi. Tras manifestarse inocentemente sorprendido del valor que el duque de Huan otorga a los libros antiguos, el humilde artesano argumenta como sigue

Vuestro servidor ve las cosas desde su humilde experiencia. Para fabricar una rueda, un golpe demasiado suave no mella; uno demasiado fuerte resbala sobre la madera. Ni muy fuerte ni muy suave: tengo el golpe en la mano y la reacción en el espíritu. Hay en ello algo que no puede explicarse con palabras. No he podido enseñárselo a mi hijo, ni él ha podido aprenderlo de mí, de modo que a mis setenta años sigo fabricando ruedas. Los antiguos se llevaron a la tumba todo cuanto no pudieron transmitir. Así, pues, lo que leéis no son sino los desechos de los antiguos. ${ }^{20}$

Del zen han existido y existen diversas escuelas y orientaciones, pero, de modo general, se puede afirmar que su idea de la iluminación súbita es uno de sus rasgos diferenciales. Desarrolladas en China desde finales del siglo V las escuelas chan se oponían a la tradicional concepción gradual del proceso ascético y sapiencial (Cheng, 352-359). Lacan está inmerso en el empeño, a partir del Seminario X, de una búsqueda que lo lleva a la desvalorización del significante y a prestar una atención cada vez más honda al valor de la dimensión carente de palabras de lo real. Oriente, y el budismo zen en particular, son algunas de las brújulas con que tratará de orientarse en los oscuros vericuetos de su recorrido.

\footnotetext{
${ }^{19}$ Lacan, Jacques. El seminario, libro 10: La angustia. Buenos Aires: Paidós, 2006:243-244.

${ }^{20}$ Citado en Cheng, Anne. Historia del pensamiento chino. Barcelona: Ediciones Bellaterra, 2002:112.
} 


\section{Mèrce Altimir}

El psicoanalista estuvo ausente durante el mes de abril y es a su vuelta a la tarea del seminario, el 8 de mayo de 1963, cuando reparte unas fotografías de estatuas budistas y las comenta con el eje de la problemática abordada en este Seminario, cuyo título es la angustia, pero cuyo aporte innovador es el objeto $a$, el objeto perdido causa del deseo.

\section{FIGURAS DEL BODHISATTVA KAN'ON 観音 (AVALOKITESHVARA)}

En la edición oficial de Seuil, publicada en el año 2004, de este seminario X, se han colado algunos errores en relación a las imágenes objeto de comentario. Se ha confundido el Gran buda (Daibutsu) del Tôdai-ji con el bodhisattva de Chûgû-ji. Repetidos tal cual en la edición al castellano de Paidós del 2006, ya hemos tenido ocasión de aclararlos con anterioridad. ${ }^{21}$ El templo de Chûgû-ji se encuentra en Nara, al este del conjunto de Hôryû-ji. Su construcción fue ordenada por el príncipe Shôtoku (572-621) y estaba destinada a convertirse en la residencia de su madre. Tras el fallecimiento de ésta, pasó a ser un monasterio femenino. La estatua del bodhisattva kan'on-nyoirin fue realizada durante el periodo Asuka (552-646). En relación a ella, Lacan comenta

Aquello de lo que se trata, al menos en la etapa intermedia de la relación con el Nirvana, está siempre articulado, de una forma extendida en toda formulación de la verdad búdica, en el sentido de un no dualismo. Si hay un objeto de tu deseo, no es más que tú mismo. No es éste, por otra parte, un rasgo original del budismo. Tan wan asi, es a ti mismo a quien reconoces en el otro, ya está escrito en el Vedanta.

Como es imposible hacer en modo alguno una historia y una crítica del budismo, sólo lo recuerdo aquí para aproximarnos, por la vía más corta, a aquello que es para nosotros utilizable de la experiencia —muy particular, como verán— que yo mismo tuve en ocasión con esa estatua. ${ }^{22}$

Hablaremos de esa "ocasión muy particular” un poco más adelante. Por el momento retrocedemos hacia atrás dos párrafos

Entramos en el budismo. Como ustedes saben, su objetivo, los principios tanto del recurso dogmático como de la práctica ascética que con ellos se puede relacionar, pueden resumirse en esta fórmula que nos interesa en el punto más crucial —el deseo es ilusión-. ¿Qué significa esto? Ilusión no puede ser aquí más que referencia al registro de la verdad. La verdad de la que se trata no puede ser una verdad última, porque queda por precisar, junto a la ilusión, la función del ser. Decir que el deseo es ilusión es decir que no tiene soporte, que no desemboca en nada, ni apunta a nada. Ahora bien, ya han oído ustedes hablar bastante, aunque sólo sea en Freud, del Nirvana, para saber que no se identifica con una pura reducción a la nada.

\footnotetext{
${ }^{21}$ Altimir, Mercè. Lacan y el mundo japonés. Cuestiones de acción traslativa, transmisión y edición. Tesis leída en junio de 2010 en el programa de doctorado de Teoría de la Traducción de la Universitat Autònoma de Barcelona. Algunos errores han sido indicados también por Takatsugu Sasaki en un libro del año 2007: Moji to mikake no kuni: Baruto to Rakan no Nihon.

${ }^{22}$ Lacan, Jacques. El seminario, libro 10: La angustia. Op. cit., 241.
} 


\section{Algunas consideraciones contextuales en torno al primer viaje a Japón}

El uso de la negación, que es corriente en el Zen, por ejemplo, mediante el recurso al mou, 無, no da lugar a engaño. Se trata de una negación bien particular, un no tener, lo cual, por sí solo, bastaría para ponernos en guardia. ${ }^{23}$

Aquí Lacan se está refiriendo con toda evidencia al significante de la falta de significante en el Otro, a la falta fálica de la madre, el vacío original que es condición de emergencia de los significantes. La otra fotografía que muestra a los asistentes al seminario es un retrato del impresionante conjunto de estatuas del templo Sanjûsangendô (Rengeô-in), un recinto situado en las montañas de Higasghiyama de Kioto. En su recinto se encuentran mil (más una) estatuas de kan'on armada de mil brazos dispuestas en doble hilera a cada lado del corredor central. Una de las curiosidades que presentan estas estatuas, precisamente la que Lacan se encarga de destacar - y lo mismo vale para el kan'on de Chûgûji- consiste en la ambigüedad de su figura, en tanto no se sabe muy bien, apelando a su apariencia, cuál de los dos sexos están representando

no todas las formas de Kwan non son femeninas, yo diría incluso que la mayoría no lo son. Ya que tienen ante ustedes la imagen de las estatuas de este templo, donde la misma santidad o divinidad — término que debe ser dejado en suspenso — está representada bajo una forma múltiple, pueden advertir que los personajes están provistos de pequeños bigotes e infinitas barbas apenas esbozadas. Tienen ahí, pues, una forma masculina, lo cual corresponde, en efecto, a la estructura canónica de lo que representan esas estatuas, con el número de cabezas y de brazos convenientes.

En la primera estatua cuyas representaciones les he hecho circular, se trata exactamente del mismo ser. Esta estatua responde a la forma especificada como una Nyo i Rin, Kwan non, Kwan ze non. Nyo i Rin significa, al igual que su correspondiente sánscrito, como la rueda de los deseos (244).

Todavía necesitamos añadir dos citas más de Lacan. La primera es una pregunta

¿Cuál es la función de la castración en este objeto, esta estatua, del tipo más turbador, por ser al mismo tiempo nuestra imagen y otra cosa, mientras que, en el contexto de una cultura determinada, aparece como algo que no tiene relación con el sexo? (247).

La segunda corresponde a la apelación que hace al testimonio de los japoneses, convocados en la ocasión en tanto soportes de la "cultura determinada" a que se ha hecho alusión en la cita anterior

Han visto ustedes la estatua, su rostro, han visto esa expresión absolutamente impactante por el hecho de que es imposible leer en ella si es toda para ustedes o permanece toda en el interior. Entonces yo no sabía qué era una Nyo i Rin, una Kwan ze non, pero hacía tiempo que había oído hablar de la Kwan yin. ${ }^{24}$ Pregunté a propósito de estas estatuas, así como de otras.

En fin, ¿Es un hombre o una mujer?

\footnotetext{
${ }^{23}$ Cfr., 241. En relación al "no tener" que Lacan invita a que no pase desapercibido, queremos hacer memoria al lector del comentario acerca de "la mujer pobre” de C. Soler.

${ }^{24}$ Se refiere a la tradición china del bodhisattva Avalokiteshvara.
} 


\section{Mèrce Altimir}

Les ahorro los debates, los rodeos de lo que se desarrolló en torno a esta pregunta, que tiene todo su sentido en Japón, les repito, puesto que los Kwan ze no están hechos todos de forma unívoca. Y entonces lo que recogí tiene algo de encuesta, en fin, algo así como el informe Kinsey, tuve la certeza de que, para este muchacho cultivado, merimeniano, maupassantesco, así como para un gran número de sus camaradas a quienes hice interrogar, la cuestión de saber ante una estatua de esta clase, si es macho o hembra, no se había planteado nunca (245:246).

Tal como se puede apreciar, Lacan está intentando suscitar la intriga en su auditorio acerca del aire hermafrodita de las figuras del bodhisattva, esos seres santos que dentro de la tradición del mahayana representan a los practicantes que, aun habiendo alcanzado el umbral de transformación definitiva, renuncian a dar el paso último decididos a permanecer en el samsara con el fin de ayudar al resto de los seres sensibles a seguir la vía.

Hemos visto que Lacan cita el sutra del loto. Hemos seleccionado unos fragmentos del mismo. ${ }^{25}$

\section{EL SUTRA DEL LOTO Y LA CUESTIÓN DE LA SUBJETIVIDAD DE LA MUJER}

Estamos hablando de una de las escrituras sagradas más importantes del budismo mahayana. Al parecer, la región noroeste de la India, Gandhāra, tuvo que ser la cuna de la gestación del texto y entre los años 50 y 150 d.c. debió adquirir la forma en que lo conocemos. La lengua utilizada es el sánscrito budista híbrido, una mezcla de sánscrito y de varios dialectos hablados durante la época de su composición. Se han encontrado manuscritos en el Nepal, Gilgit (en el actual Pakistán) y en Asia central. Limitaremos nuestro comentario a los pasajes que interesan particularmente al tema tratado. En primer lugar, la cita en que se explica el milagro de la transformación en varón de una niña de virtudes excepcionales para su sexo

Dudas de Shāriputra

Y entonces el venerable Shāriputra a la hija del rey de Sāgara, el rey de los Nāgas, le dijo esto: "Oh hija de familia, sólo ha surgido en ti la Mente de Iluminación, posees una sabiduría ilimitada, incapaz de decaer, pero la condición de Perfectamente Iluminado es difícil de obtener. Oh hija de familia, puede ser que una mujer no deje relajarse su energía, y que durante innumerables centenares de Períodos Cósmicos, durante innumerables millares de Períodos Cósmicos, haga méritos, realice en su integridad las Seis Perfecciones, pero ni aún después de esto puede obtener la condición de Buda. ¿Por qué razón? Hay cinco condiciones que aún después de eso la mujer no puede obtener, ¿Cuáles son esas cinco? Primero, la condición de Brahmā; segundo la condición de Shakra; tercero, la condición de Māhāraja; cuarto la condición de Chakravartin; quinto la condición de un Bodhisattva ya no expuesto a decaer.

25 Procedentes de la traducción realizada en 1999 por Carmen Dragonetti y Fernando Tola. Dragonetti, Carmen. (Eds.). El sūtra del loto de la verdadera doctrina: Saddharmapundarīksūtra. México: El Colegio de México, 1999. 


\section{Algunas consideraciones contextuales en torno al primer viaje a Japón}

[...] La hija del rey de los Nāgas se convierte en hombre y llega a ser un Bodhisattva

Y entonces, la hija de Sāgara, el Rey de los Nāgas, ante todo el mundo y ante el Anciano Shāriputra, hizo desaparecer en ella sus atributos de mujer y aparecer atributos de hombre, y se mostró a sí misma convertida en un Bodhisattva. ${ }^{26}$

Nos encontramos con una operación inversa a la de Tiresias de la tradición griega, en la que la transformación acontece de varón a mujer y es valorada como ganancia. De beneficio de placer, no de santidad, razón por la cual a ella le debe estar intrínsecamente vedado el alcance de la meta última. Lo cual nos da una clave de la minusvaloración tradicional de la mujer, una consecuencia de asociar la cultura el ser femenino al sexo, y de la raíz del principal obstáculo en el camino de ascesis: también el sexo. Véase este otro pasaje, que evoca la felicidad del Mundo Sukhāvatī
Ahí no existen las mujeres,
Ni tampoco para nada la relación sexual:
Los hijos auténticos del Victorioso
Son seres espontáneos, puros,
Sentados en el interior de lotos (485).

Una nota de los traductores nos aclara que la expresión "seres espontáneos" hace referencia a seres que nacen sin necesidad de una pareja que les de nacimiento.

Como se ve, hay en la tradición de la vía ascética del budismo y del boshisattva una voluntad de suprimir la sexualidad, incluso de borrar, como ponen de manifiesto las estatuas recogidas por la cámara fotográfica de Lacan, su origen natural, la reproducción sexuada. Este es el escamoteo que Lacan criticará tanto en relación al budismo como en la práctica de muchos psicoanalistas. Y una indicación tan precisa como ésta sirve para recordarnos el hecho de que precisamente el escándalo de la invención freudiana, incluso a pesar de las derivas de su fundador, consistió en el reconocimiento de la incidencia de la diferencia sexual en el ser humano. A lo que hay que añadir el temor a uno de los sexos, el femenino, tanto por parte tanto de la misma mujer como, también y más decisivamente, por parte de su pareja masculina, y los motivos de su generalizada relegación social y cultural.

\section{RECAPITULACIÓN}

Oriente es todavía uno de los espejos en que se contempla occidente, una tierra de fascinación y de amenaza. El filósofo alemán Friedrich Schlegel puede servir de paradigma del acercamiento europeo al lejano oriente. Tras desplegar un enorme entusiasmo al inicio acaba rechazándolo posteriormente con pareja intensidad. Resulta difícil sustraerse a los efectos, ya sean de embeleso o de estafa, que comporta la no intencionada trampa de engaños que se disputa en el tablero de juego que compartimos con la alteridad.

La filosofía de Schopenhauer, leída por Freud y sus contemporáneos, al coincidir

\footnotetext{
${ }^{26}$ Dragonetti, Carmen; Tola, Fernando (eds.), op. cit., 289-290.
} 


\section{Mèrce Altimir}

aparentemente en algunos puntos con el budismo, difundió uno de los estereotipos del mismo, una visión pasiva y pesimista de la vida. El psicoanalista austríaco no estuvo dispuesto a seguirle por esa senda. De otro lado, Japón, ausente de las controversias budistas hasta que, ya entrado el siglo XX, llega a Europa el impacto del zen, apenas aparece mencionado en ninguna de sus obras. Lacan, en cambio viajará en dos ocasiones al archipiélago oriental. El psicoanálisis lacaniano nos enseña que si hay algo que enferma la vida, si sufrimos por esa poquedad de vida, "living nor dead", que constituye la amarga lamentación de The Waste Land, se debe a la incidencia sobre la carne de la verdad y su aparejo de palabras. Para sacar a la luz semejante idea, Lacan, como todo gran pensador, se vio obligado a trazar recorridos sinuosos.

Para este primer examen de la influencia del lejano oriente en la obra del psicoanalista francés hemos preferido dilucidar tanto, y muy en particular, los antecedentes freudianos como también el contexto europeo. Esto último nos ha conducido al comentario del poema de Eliot, lleno de resonancias orientales y que tanta influencia tuvo en la generación de los que vivieron su juventud, Lacan entre ellos, en el momento posterior a la primera guerra europea. Las tetas de Tiresias constituyen una nota de aviso, un llamamiento urgente a la reconsideración de la función social de la mujer, tradicional representante del sexo frente a la cultura y el orden social, razón por la cual las vías ascéticas orientales y occidentales, en un escamoteo sistemático, la reenvían al lugar de residuo marginal y vigilado de las heterodoxias.

Lacan volvió una vez más a Japón en 1971. A su retorno, no nos hablará ya del budismo. Su interés, cuyo comentario dejamos para una ocasión futura, se ha desplazado del lado de la escritura y de la caligrafía. Para finalizar, nos gustaría recapitular con la idea de que para el psicoanalista francés el lejano oriente fue en todo momento una fuente de inspiración y de contrapunto a la tradición occidental.

Universitat Autònoma de Barcelona*

Facultad de Traducción e Interpretación Edificio K-1009 Campus de la Universitat Autònoma de Barcelona 08193 Bellaterra (Cerdanyola del Vallès) Barcelona (España) merce.altimir@uab.cat 
Algunas consideraciones contextuales en torno al primer viaje a Japón

\section{BIBLIOGRAFÍA}

Altimir, Mercè. Lacan y el mundo japonés: Cuestiones de acción traslativa, transmisión y edición. Bellaterra: Universidad Autónoma de Barcelona, 2010. Tesis doctoral.

Cheng, Anne. Historia del pensamiento chino. Barcelona: Bellaterra, 2002.

Dragonetti, Carmen; Tola, Fernando (Eds.). El sūtra del loto de la verdadera doctrina: Saddharmapundarīksūtra. México: El Colegio de México, 1999.

Eliot, Thomas Stearns. La tierra baldía. Madrid: Cátedra, 2005.

Frazer. James George. La rama dorada. México: F.C.E., 1944.

Freud, Sigmund. Moises y la religión monoteísta. Obras completas. Vol. XXIII. Buenos Aires: Amorrortu, 1985.

------ El malestar en la cultura. Obras completas. Vol. XXI. Buenos Aires: Amorrortu, 1985.

------ Tótem y tabú. Algunas concordancias en la vida anímica de los salvajes y de los neuróticos. Obras completas. Vol. XIII. Buenos Aires: Amorrortu, 1985.

Fromm, Erich; Suzuki, Daisetsu Teitarô. Budismo zen y psicoanálisis. México: F.C.E., 1964.

Gutiérrez, Fernando G. Summa artis. El arte de Japón. Vol. XXI. Madrid: EspasaCalpe, 1973.

Izutsu, Toshihiko. Hacia una filosofía del budismo zen. Madrid: Trotta, 2009.

Jones, Ernest. Vida y obra de Sigmund Freud. $4^{\mathrm{a}}$ ed. Vol. I-III. Buenos Aires: Paidós, 1989.

Kodansha Encyclopedia of Japan. Tokyo: Kodansha, 1983.

Lacan, Jacques. El seminario, libro X: La angustia. Buenos Aires: Paidós, 2006.

----- Escritos. Vol. I. Madrid: Siglo XXI, 1995.

Lenoir, Frédéric. El budismo en Occidente. Barcelona: Seix Barral, 2000.

Marqués Rodilla, Cristina. El acontecimiento del amor. De la insuficiencia del goce. Madrid: Biblioteca Nueva, 2006.

Roudinesco, Élisabeth. Jacques Lacan: Esbozo de una vida, historia de un sistema de pensamiento. Barcelona: Anagrama, 1995.

Sasaki, Takatsugu. Moji to mikake no kuni: Baruto to Rakan no Nihon. Tokyo: Taiyo Shuppan, 2007.

Shingu, Kazushige. "Freud, Lacan and Japan”. The Letter: Lacanian Perspectives on Psychanalysis, 34, 2005:48-62.

Soler, Colette. Lo que Lacan dijo de las mujeres. Buenos Aires: Paidós, 2006.

Zafiropoulos, Markos. La declinación del padre (1938-1953). Buenos Aires: Nueva Visión, 2002. 